\title{
A formação do pediatra como mediador nos casos de crianças e adolescentes com distúrbios de desenvolvimento e transtornos mentais
}

\section{The training of the pediatrician as a mediator in the cases of children and adolescents with developmental disturbances and mental disorders}

Jairo Werner Júnior ${ }^{1}$

'Universidade Federal Fluminense

No Brasil, com a queda das taxas de morbimortalida$\mathrm{de}^{1}$ da população infantil, aumentou a necessidade e a oportunidade de pediatras atuarem no campo da saúde mental, incluindo a possibilidade, com a capacitação adequada, de atenderem nos Centros de Atenção Psicossocial Infantojuvenil (CAPSi). ${ }^{2}$

$\mathrm{O}$ artigo Habilidades dos residentes de pediatria na abordagem dos transtornos mentais na infância, publicado neste número da Revista de Pediatria SOPERJ, chama a atenção para o fato de o treinamento dos médicos-residentes ser considerado insuficiente para abordar esses transtornos. Corroborando a percepção dos residentes pesquisados sobre a alta prevalência dos transtornos mentais, a Organização Mundial da Saúde ${ }^{3}$ destaca que, em todo o mundo, "até $20 \%$ das crianças e adolescentes sofrem de uma doença mental incapacitante" e que, além disso, "o suicídio em todo o mundo é a terceira principal causa de morte entre os adolescentes".

Diante de expressiva demanda, o desempenho do pediatra precisaria ir além do objetivo de identificar e encaminhar os casos de suspeita de transtornos mentais e de comportamento. O pediatra, por ser o primeiro profissional de saúde que acompanha de perto a criança e a relação pais-filho, deve ser capaz de atuar em qualquer situação que coloque em risco o desenvolvimento infantil, por exemplo episódios de depressão materna pós-parto.

Novas demandas têm chegado ao pediatra, tais como a questão do uso excessivo de telas eletrônicas ${ }^{4}$ - que podem vir a causar danos tanto à saúde física (obesidade, dor lombar e ausência de exercícios) quanto à saúde mental (agitação, ansiedade, hiperatividade, dificuldade de comunicação, dificuldade de sono, dependência) de crianças e adolescentes -, criando desarmonias evolutivas importantes.

É o caso de menino de três anos e meio, que, ao ingressar na creche, foi encaminhado ao pediatra com suspeita de autismo, pois apresentava dificuldade de interação e comunicação. A causa identificada, entretanto, foi a ausência de interação social adequada, pois o menino nos seus primeiros anos de vida interagiu basicamente com tablets e outros dispositivos eletrônicos.

A formação do pediatra deve prepará-lo para assumir, sempre em cooperação com a família e a escola, papel relevante na promoção da saúde mental de sua clientela, contribuindo, inclusive, para evitar o excesso de diagnósticos e modismos psicopatológicos relacionados ao comportamento da criança e do adolescente - em processo de transformação permanente. ${ }^{5}$

A questão que se coloca, diante dessa realidade, é como concretizar a necessária e urgente formação do pediatra nesse campo, sem cair, entretanto, no reducionismo superficial que rotula a criança e angustia os pais? Ao considerar o pediatra como responsável pelo acompanhamento global da criança, a formação pediátrica efetiva deveria fornecer os fundamentos sobre as leis gerais da ciência do desenvolvimento infantil, como expresso 
na pedologia de Vigotski. ${ }^{6} \mathrm{O}$ objetivo é possibilitar que o pediatra articule as relações biológicas, psicossociais e culturais associadas ao desenvolvimento das funções psíquicas superiores e aos outros aspectos do desenvolvimento humano.

Com a necessária preparação, o pediatra poderá atuar com perícia e segurança na abordagem de atrasos, desvios do desenvolvimento e transtornos mentais e de comportamento, tornando-se excelente mediador entre a família, a criança e as outras especialidades/áreas envolvidas.

\section{REFERÊNCIAS}

1 Instituto Brasileiro de Geografia e Estatística, Departamento da População e Indicadores Sociais. Evolução e perspectivas da mortalidade infantil no Brasil. Rio de Janeiro: IBGE; 1999. Disponível em: http://www.blog.saude.gov.br/priucs

2 Hoffmann MCCL, Santos DN, Mota ELA. Caracterização dos usuários e dos serviços prestados por Centros de Atenção Psicossocial Infantojuvenil. Cadernos de Saúde Pública. 2008;24(3):633-42. DOI: http://dx.doi.org/10.1590/ S0102-311X2008000300017

3 World Health Organization. Caring for children and adolescent with mental disorders: setting WHO directions. Geneva, 2003. Available from: http://Www.who.int/mental_health/media/ en/785.pdf

4 Werner J. Linguagem tecnológica e mediação social na formação da mente. In: Barr MA (Org.). Cuidadores da primeira infância: por uma formação de qualidade. Brasília: Senado Federal; 2017. p. 113-25.

5 Frances A. Fundamentos do diagnóstico psiquiátrico: respondendo às mudanças do DSM-5. Porto Alegre: Artmed; 2015. p. 5, 15.

6 Prestes Z, Tunes E (Org./Trad.). Sete aulas de L. S. Vigotski sobre os fundamentos da pedologia. Rio de Janeiro: E-Papers; 2018. 